\title{
Prediksi Produksi Kayu Bundar Kabupaten Malang dengan Menggunakan Metode Markov Chains
}

\author{
Ikhtiyari Navila Rizanti dan Soehardjoepri \\ Departemen Matematika, Fakultas Matematka dan Ilmu Pengetahuan Alam, Institut Teknologi \\ Sepuluh Nopember (ITS) \\ e-mail: djoepri.its@gmail.com
}

\begin{abstract}
Abstrak - Kayu bundar banyak ditemukan sebagai bahan dasar dalam pembuatan furniture misalnya meja, kursi, garasi, dan sebagainya. Produksi kayu bundardiperlukan suatu model matematika untuk menghitung prediksi pada periode yang akan mendatang untuk mempermudah pemerintah dan perusahaan kayu dalam mengambil setiap kebijakannya terkait manajemen hasil produksi kayu bundar. Metode Markov Chains dapat digunakan sebagai salah satu metode untuk memprediksikan hasil produksi kayu bundar di Kabupaten Malang beberapa periode kedepan dengan menggunakan data-data yang sudah ada. Data-data yang digunakan adalah data hasil produksi kayu yang tercatat oleh Perum Perhutani Divisi Regional Jawa Timur pada Januari 2010 sampai dengan Mei 2017. Dalam hal ini, produksi kayu bundar di Kabupaten Malang akan mengambil 4 sampel pohon yang meghasilkan kayu rimba yaitu Pinus, Mahoni, Sengon, dan Damar. Dari simulasi didapat prediksi beberapa periode kedepan dengan menggunakan pembagian 3 state, 4 state, dan 5 state, dan juga mendapatkan peluang dari periode keberapa mengalami steady state dari 4 sampel kayu dari pohon rimba diatas. Pembagi 3 state yang paling cocok digunakan untuk keempat jenis kayu, karena memiliki kesesuaian hasil prediksi dengan data aktual yang cukup tinggi.
\end{abstract}

Kata Kunci-Hutan Produksi, Kayu Bundar, Markov Chains, Prediksi.

\section{PENDAHULUAN}

$\mathrm{H}$ UTAN merupakan salah satu sumber daya alam yang sangat bermanfaat pagi kehidupan manusia. Pengelolaan hutan pula merupakan sebuah usaha yang dilakukan untuk memperoleh manfaat dari adanya hutan tanpa mengabaikan dari sisi kelestariannya.Indonesia memiliki berbagai macam kayu yang sebagian besar digunakan dalam bidang pembangunan.Dimana Indonesia adalah negara yang dapat dikatakan memiliki pengelolaan hutan yang berskala besar.Salah satu yang dihasilkan oleh pengelolaan hutan produksi adalah kayu.Kayu berperan penting, yaitu sebagai bahan dasar dalam pembuatan rumah, dan kerajianan ukir kayu juga banyak yang dihasilkan oleh masyarakat Indonesia.

Tercatat Indonesia berada diurutan ke-9 negara yang memiliki hutan terluas di dunia, dengan luas hutan mencapai $884.950 \mathrm{~km}^{2}$ [1]. Salah satu produksi hutan yang dikelola oleh BUMN (Badan Usaha Milik Negara) adalah kayu bundar.Perusahaan pengelola hutan BUMN yang ada di Indonesia adalah Perum Perhutani yang berada di Pulau Jawa.Dengan memiliki 3 divisi wilayah kerja yaitu Regional Jawa Barat dan Banten, Regional Jawa Tengah, dan Regional Jawa Timur. Jawa Timur merupakan divisi regional terluas kawasan hutannya, dengan luas $1.133 .836,39 \mathrm{Ha}$ [2].
Jumlah kayu milik Indoneisa yang telah diekspor mengalami naik turun ke berbagai daerah atau negara tujuan, tercatat oleh Badan Pusat Statistik pada tahun 2000 hingga 2015 [3].

Salah satu faktor yang menyebabkan naik turunnya jumlah ekspor kayu adalah hasil produksi kayu. Karena adanya fluktuasi pada jumlah kayu yang diekspor, maka dibutuhkan prediksi untuk menghitung hasil kayu yang dapat diproduksi di tahun mendatang.

Karena Malang adalah salah satu kabupaten yang memiliki luas hutan terbesar yang ada di regional Jawa Timur, maka perlu memprediksi hasil produksi kayu di Kabupaten Malang. Maka diperlukan suatu model matematika untuk memprediksi hasil produksi kayu untuk beberapa tahun kedepan. Telah banyak penilitian yang dilakukan untuk prediksi dalam berbagai bidang dengan menggunakan metode Markov Chains, salah satunya adalah prediksi pada tanaman palawija di Kabupaten Indragiri Hilir. Sehingga metode Markov Chains dapat digunakan untuk membantu dalam memperkirakan perubahan yang mungkin terjadi pada waktu yang akan mendatang dengan menggunakan variabel-variabel dinamis pada waktu yang lalu. Jenis kayu bundar yang akan dijadikan sampel yaitu kayu rimba berupa Pinus, Mahoni, Sengon, dan Damar. Sehingga dalam tugas akhir ini akan dilakukan prediksi hasil produksi kayu bundar, terutama kayu rimba dengan menggunakan metode Markov Chains di Kabupaten Malang.

\section{URAIAN PENELITIAN}

\section{A. Landasan Teori}

\section{Markov Chains}

Rantai markov merupakan suatu teknik probabilitas yang dapat menganalisis pergerakan dari satu kondisi ke kondisi lainnya.Teknik ini dapat digunakan juga untuk menganalisis kejadian-kejadian di waktu-waktu mendatang secara matematis.Dimana konsep dasar Marcov Chains pertama kali diperkenalkan oleh seorang matematisi Rusia Andrei A. Marcov pada tahun 1907 [4].

\section{Matriks Probabilitas Transisi}

Keadaan transisi merupakan perubahan dari suatu keadaan (state) ke state lainnya pada periode berikutnya, dimana pada keadaan transisi ini adalah suatu proses random dan dinyatakan dalam bentuk probabilitas. Maka probabilitas ini dinamakan dengan probabilitas transisi yang digunakan untuk menentukan probabilitas keadaan atau periode berikutnya. 
$P=\left[p_{i j}\right]_{N \times N}=\left[\begin{array}{cccc}p_{11} & p_{12} & \ldots & p_{1 N} \\ p_{21} & p_{22} & \ldots & p_{2 N} \\ \vdots & \vdots & \vdots & \vdots \\ p_{N 1} & p_{N 2} & \ldots & p_{N N}\end{array}\right]$

Teorema 2.1 (Sifat Matriks Transisi)

Diberikan $P=\left[p_{i, j}\right]$ menjadi probabilitas matriks transisi $N \times N$ pada DTMC $\left\{X_{n}, n \geq 0\right\}$ dengan state space $S=$ $\{1,2, \ldots, N\}$ maka:

1. $p_{i j} \geq 0,1 \leq i, j \leq N$

2. $\sum_{j=1}^{N} p_{i j}=1,1 \leq i \leq N$

Probabilitas transisi $n$-step memenuhi persamaan berikut, disebut dengan pesamaan Chapman-Kolmogorov:

$$
p_{i, j}^{(n+m)}=\sum_{k=1}^{N} p_{i, k}^{(n)} p_{k, j}^{(m)}
$$

dari persamaan diatas dapat dinyatakan menjadi, $P^{(m+n)}=$ $P^{(n)} * P^{(m)}$.

$P^{(n+1)}=P^{(n)} * P$.

Untuk $n=0$ didapat persamaan,

$$
\begin{gathered}
P^{(1)}=P^{(0)} * P \\
P^{(2)}=P^{(1)} * P=P^{(0)} * P * P=P^{(0)} * P^{2} \\
\vdots \\
P^{(n)}=P^{(n-1)} * P=\cdots=P^{(0)} * P^{n}
\end{gathered}
$$

Dari formula rekursif diatas sehingga didapat persamaan:

$$
P^{(n+1)}=P^{(0)} * P^{n+1}
$$

Formula rekursif tersebut dapat dicapai ramalan yang berdasarkan interperetasi sistem dinamik [3].

\section{B. Transient Behaviour of Discrete-Time Markov Chains}

Jika P merupakan probabilitas dan $\pi_{0}$ sebagai titik acuan, maka nilai $\pi_{n}$ bisa didapat dengan rumus:

$$
\begin{gathered}
\pi_{n}=\pi_{(n-1)} P \\
\pi_{(n-1)}=\pi_{(n-2)} P ; \pi_{(n-2)}=\pi_{(n-3)} P \\
\vdots
\end{gathered}
$$

Karena terjadi pengulangan maka bisa dinyatakan dengan rumus

$$
\pi_{n}=\pi_{0} P^{n}[5]
$$

\section{Peluang Steady State}

Peluang steady state merupakan peluang peralihan di masa depan yang tidak bergantung pada keadaan awal. Dimana peluang ini adalah peluang peralihan yang sudah mencapai keseimbangan sehingga tidak akan berubah terhadapt perubahan waktu yang terjadi. Prinsip ini digunakan untuk mengamati berapa state untuk menuju titik seimbang. Sehingga didapat n-langkah yang akan menjadi steady state [6]. Syarat-syarat steady state adalah distribusi stasioner, bersifat ergodik, dan interlinked property of state [7].

Berdasarkan metodologi penelitian, langkah-langkah aplikasi rantai Markov antara lain:

1. Dapat menampilkan dan menggunakan data awal (data yang sudah ada).

2. Pembentukan interval dan state, menentukan probabilitas state dan probabilitas transisi, dan menulis state matriks probabilitas transisi dengan tranfer state.

3. Melakukan simulasi

4. Menganalisis hasil dari simulasi

\section{PEMBAHASAN}

\section{A. Pembagian 3 State}

1. Kayu Pinus

Untuk mencari probilitas state $p_{i}=\frac{s_{i}}{n}$, n adalah banyaknya data [8]. Dengan $n=174$, kemudian mencari selisih dari nilai maksimal dan minimal untuk mendapatkan interval tiap state. Data yang termasuk pada $S_{1}$ sebanyak 155 data, $S_{2}$ sebanyak 16 data, dan untuk $S_{3} 3$ data. Kemudian dibagi dalam 3 interval jumlah produksi kayu dan didapat hasil sebagai berikut:

Tabel 1.

Pembagian 3 State dan Probabilitas Kayu Pinus

\begin{tabular}{cccc}
\hline \hline State & Interval & Probabilitas & Nilai \\
\hline$S_{1}$ & $X<671.76$ & $p_{1}$ & 0.8908 \\
$S_{2}$ & {$[671.76,1343.52)$} & $p_{2}$ & 0.092 \\
$S_{3}$ & $X \geq 1343.52$ & $p_{3}$ & 0.0172 \\
\hline \hline
\end{tabular}

Probabilitas transisi masing-masing state terhadap banyaknya setiap state, yakni $p_{i j}=\frac{s_{i-j}}{s_{i}}$. Sehingga dapat dibentuk matriks probabilitas transisi.Pada Maret 2017 produksi kayu masuk pada interval $S_{1}$ dan tidak ada transisi state terakhir, maka banyak data yang termasuk $S_{1}$ adalah 154 data, $S_{2} 16$ data, dan $S_{3} 3$ data. Berikut merupakan probabilitas transisi kayu Pinus:

Tabel 2.

Probabilitas Transisi 3 State Kayu Pinus

\begin{tabular}{cccc}
\hline \hline Transisi State & $\begin{array}{c}\text { Banyak } \\
\text { transisi }\end{array}$ & Probabilitas & Nilai \\
\hline$S_{1-1}$ & 147 & $p_{1-1}$ & 0.9545 \\
$S_{1-2}$ & 7 & $p_{1-2}$ & 0.0455 \\
$S_{1-3}$ & 0 & $p_{1-3}$ & 0 \\
$S_{2-1}$ & 6 & $p_{2-1}$ & 0.375 \\
$S_{2-2}$ & 8 & $p_{2-2}$ & 0.5 \\
$S_{2-3}$ & 2 & $p_{2-3}$ & 0.125 \\
$S_{3-1}$ & 1 & $p_{3-1}$ & 0.3333 \\
$S_{3-2}$ & 1 & $p_{3-2}$ & 0.3333 \\
$S_{3-3}$ & 1 & $p_{3-3}$ & 0.3333 \\
\hline \hline
\end{tabular}

Dari Tabel 2, berikut ini diperoleh matriks probabilitas transisi state yang berukuran $3 \times 3$ untuk 3 state:

$$
\begin{aligned}
P & =\left(\begin{array}{ccc}
0.9545 & 0.0455 & 0 \\
0.375 & 0.5000 & 0.125 \\
0.3333 & 0.3333 & 0.3333
\end{array}\right) \\
\pi_{1} & =\pi_{0} * P=\left[\begin{array}{lll}
1 & 0 & 0
\end{array}\right] *\left[\begin{array}{ccc}
0.9545 & 0.0455 & 0 \\
0.375 & 0.5000 & 0.125 \\
0.3333 & 0.3333 & 0.3333
\end{array}\right] \\
& =\left[\begin{array}{lll}
0.9545 & 0.0455 & 0
\end{array}\right]
\end{aligned}
$$

Dengan menggunakan persamaan (1), sehingga dengan menggunakan software MATLAB didapat

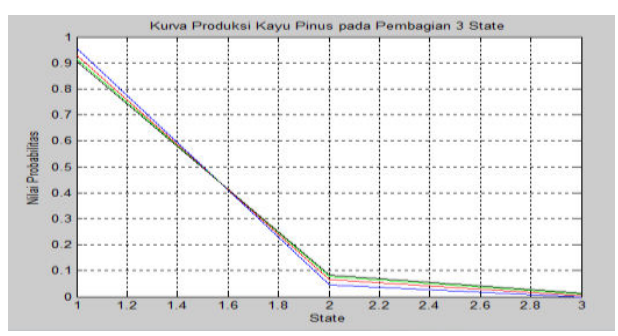

Gambar 1. Kurva produksi kayu pinus pada pembagian 3 state untuk 4 periode berikutnya. 
Selanjutnya didapat matriks probabilitas transisi n-langkah $3 \times 3$ pada saat steady state:

$$
\begin{aligned}
& \pi=\pi \mathrm{P} \\
& {\left[\pi_{1} \pi_{2} \pi_{3}\right]=\left[\pi_{1} \pi_{2} \pi_{3}\right]\left[\begin{array}{ccc}
0.9545 & 0.0455 & 0 \\
0.375 & 0.5000 & 0.125 \\
0.3333 & 0.3333 & 0.3333
\end{array}\right]} \\
& \pi_{1}=0.9545 \pi_{1}+0.375 \pi_{2}+0.3333 \pi_{3} \\
& \pi_{2}=0.0455 \pi_{1}+0.5 \pi_{2}+0.3333 \pi_{3} \\
& \pi_{3}=0.125 \pi_{2}+0.3333 \pi_{3} \\
& \pi_{1}+\pi_{2}+\pi_{3}=1
\end{aligned}
$$

Dari persamaan (3.3) didapat $0.6667 \pi_{3}=0.125 \pi_{2}$ maka $\pi_{3}=0.1875 \pi_{2}$

Dari persamaan (3.1) dan (3.2) dieleminasi menjadi

$$
\pi_{1}=9.6154 \pi_{2}
$$

Subtitusikan pada persamaan (3.4)

$$
\begin{gathered}
\pi_{1}+\pi_{2}+\pi_{3}=1 \\
9.6154 \pi_{2}+\pi_{2}+0.1875 \pi_{2}=1 \\
\pi_{2}=0.092568 \\
\pi_{1}=0.890078 \\
\pi_{3}=0.017357
\end{gathered}
$$

Bilangan terbatas dimana $\mathrm{n}=25$ sehingga setiap state dapat tercapai dari state lainnya dengan $\mathrm{n}=25$

$$
\begin{aligned}
P_{i j}^{25}= & \left.\begin{array}{lll}
0.8901 & 0.0925 & 0.0173 \\
0.8901 & 0.0925 & 0.0173 \\
0.8901 & 0.0925 & 0.0173
\end{array}\right] \\
\text { Tabel 3. } &
\end{aligned}
$$

\begin{tabular}{cccc}
\hline \hline No & Bulan & Prediksi & Produksi \\
\hline 1 & I April 2017 & $X<671.76$ & 209.72 \\
2 & II April 2017 & $X<671.76$ & 309.41 \\
3 & I Mei 2017 & $X<671.76$ & 241.64 \\
4 & II Mei 2017 & $X<671.76$ & 53.87 \\
\hline \hline
\end{tabular}

Pada Tabel 3 terlihat bahwa prediksi kayu Pinus 4 periode kedepan memiliki kecocokan dengan data $100 \%$ saat menggunakan pembagi 3 state. Dan juga untuk kayu Mahoni dan Sengon, memiliki kecocokan $100 \%$ akan tetapi untuk kayu Damar 75\%.

\section{B. Pembagian 4 State}

1. Kayu Pinus

Pada pembagian 4 state langkah penyelesaiannya sama dengan pembagi 3 state akan tetapi selisihnya dibagi 4 untuk mendapatkan interval masing-masing state.

Tabel 4.

Pembagian 4 State dan Probabilitas Kayu Pinus

\begin{tabular}{rccl}
\multicolumn{4}{c}{ Pembagian 4 State dan Probabilitas Kayu Pinus } \\
\hline \hline State & Interval & Probabilitas & Nilai \\
\hline$S_{1}$ & $X<503.82$ & $p_{1}$ & 0.8506 \\
$S_{2}$ & {$[503.82,1007.64)$} & $p_{2}$ & 0.1092 \\
$S_{3}$ & {$[1007.64,1511.46)$} & $p_{3}$ & 0.023 \\
$S_{4}$ & $X \geq 1511.46$ & $p_{4}$ & 0.0172 \\
\hline \hline
\end{tabular}

$$
\begin{gathered}
P=\left(\begin{array}{cccc}
0.9320 & 0.0544 & 0.0136 & 0 \\
0.4211 & 0.4211 & 0.0526 & 0.1053 \\
0.5000 & 0.5000 & 0 & 0 \\
0 & 0.3333 & 0.3333 & 0.3333
\end{array}\right) \\
\pi_{1}=\pi_{0} * P
\end{gathered}
$$

$$
\begin{gathered}
=\left[\begin{array}{lllll}
1 & 0 & 0 & 0 & 0
\end{array}\right] *\left[\begin{array}{cccc}
0.9320 & 0.0544 & 0.0136 & 0 \\
0.4211 & 0.4211 & 0.0526 & 0.1053 \\
0.5000 & 0.5000 & 0 & 0 \\
0 & 0.3333 & 0.3333 & 0.3333
\end{array}\right] \\
=\left[\begin{array}{lllll}
0.9320 & 0.0544 & 0.0136 & 0
\end{array}\right]
\end{gathered}
$$

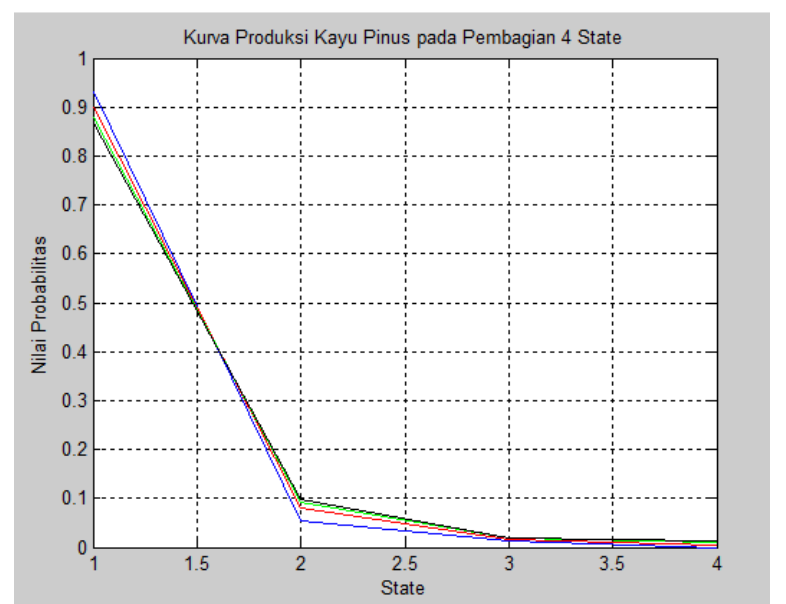

Gambar 2. Kurva produksi kayu pinus pada pembagian 4 state untuk 4 periode berikutnya.

Kemudian didapat matriks probabilitas transisi n-langkah $4 \times 4$ pada saat steady state dengan menggunakan cara yang sama didapat pada $\mathrm{n}=21$ :

$$
P_{i j}^{21}=\left[\begin{array}{llll}
0.8497 & 0.1098 & 0.0231 & 0.0173 \\
0.8497 & 0.1098 & 0.0231 & 0.0173 \\
0.8497 & 0.1098 & 0.0231 & 0.0173 \\
0.8497 & 0.1098 & 0.0231 & 0.0173
\end{array}\right]
$$

Nilai Prediksi Kayu Pinus April Mei 2017 Pembagi 4 state

\begin{tabular}{cccc}
\hline No & Bulan & Prediksi & Produksi \\
\hline 1 & I April 2017 & $X<503.82$ & 209.72 \\
2 & II April 2017 & $X<503.82$ & 309.41 \\
3 & I Mei 2017 & $X<503.82$ & 241.64 \\
4 & II Mei 2017 & $X<503.82$ & 53.87 \\
\hline \hline
\end{tabular}

Dari Tabel 5 telihat bahwa prediksi kayu Pinus 4 periode kedepan bulan April sampai dengan Mei 2017 berada di interval pertama $X<503.8$, sehingga hasil prediksi dengan data yang ada memiliki kecocokan sebesar $100 \%$ saat pembagi 4 state. Dan juga untuk kayu Mahoni 100\%, Damar $50 \%$, akan tetapi untuk kayu Sengon tidak memiliki kecocokan.

\section{Pembagian 5 State}

Pada pembagian 5 state langkah penyelesaiannya sama dengan pembagi 3 state akan tetapi selisihnya dibagi 5 untuk mendapatkan interval masing-masing state. Berikut merupakan pembagian interval pada kayu Pinus:

Tabel 6.

Pembagian 5 State dan Probabilitas Kayu Pinus

\begin{tabular}{rccc}
\hline \hline State & Interval & Probabilitas & Nilai \\
\hline$S_{1}$ & $X<403.056$ & $p_{1}$ & 0.7816 \\
$S_{2}$ & {$[403.056,806.112)$} & $p_{2}$ & 0.1437 \\
$S_{3}$ & {$[806.112,1209.168)$} & $p_{3}$ & 0.0517 \\
$S_{4}$ & {$[1209.168,1612.224)$} & $p_{4}$ & 0.0057 \\
$S_{5}$ & $X \geq 1612.224$ & $p_{5}$ & 0.0172 \\
\hline \hline
\end{tabular}




$$
\begin{aligned}
P & =\left(\begin{array}{ccccc}
0.9185 & 0.0593 & 0.0222 & 0 & 0 \\
0.32 & 0.56 & 0.08 & 0 & 0.04 \\
0.3333 & 0.2222 & 0.3333 & 0 & 0.1111 \\
0 & 0 & 1 & 0 & 0 \\
0 & 0.3333 & 0 & 0.3333 & 0.3333
\end{array}\right) \\
\pi_{1} & =\pi_{0} * P \\
& =\left[\begin{array}{lllll}
0.9185 & 0.0593 & 0.0222 & 0 & 0
\end{array}\right]
\end{aligned}
$$

Dengan menggunakan $\pi_{i+1}=\pi_{i} * P$, didapat kurva sebagai berikut:

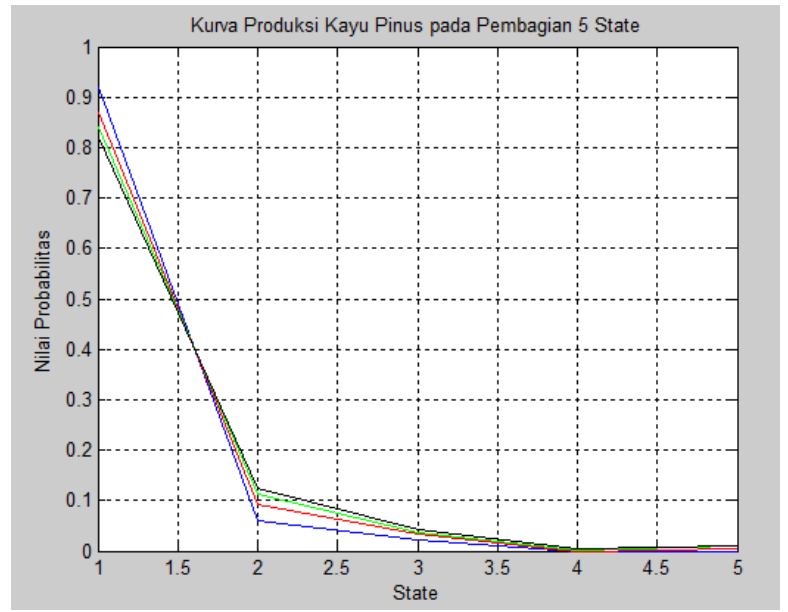

Gambar 3. Kurva Produksi Kayu Pinus pada Pembagian 5 State untuk 4 Periode Berikutnya

Selanjutnya didapat matriks probabilitas transisi n-langkah $5 \times 5$ pada saat steady state di $\mathrm{n}=28$ :

$$
P_{i j}^{28}=\left[\begin{array}{lllll}
0.7803 & 0.1445 & 0.0520 & 0.0058 & 0.0173 \\
0.7803 & 0.1445 & 0.0520 & 0.0058 & 0.0173 \\
0.7803 & 0.1445 & 0.0520 & 0.0058 & 0.0173 \\
0.7803 & 0.1445 & 0.0520 & 0.0058 & 0.0173 \\
0.7803 & 0.1445 & 0.0520 & 0.0058 & 0.0173
\end{array}\right]
$$

Tabel 7.

Nilai Prediksi Kayu Pinus April Mei 2017 Pembagi 5 state

\begin{tabular}{rlcc}
\hline \hline No & Bulan & Prediksi & Produksi \\
\hline 1 & I April 2017 & $X<403.056$ & 209.72 \\
2 & II April 2017 & $X<403.056$ & 309.41 \\
3 & I Mei 2017 & $X<403.056$ & 241.64 \\
4 & II Mei 2017 & $X<403.056$ & 53.87 \\
\hline \hline
\end{tabular}

Dari Tabel 3.7 telihat bahwa prediksi kayu Pinus 4 periode kedepan bulan April sampai dengan Mei 2017 berada di interval pertama $X<403.056$, sehingga hasil prediksi dengan data yang ada memiliki kecocokan sebesar $100 \%$ saat pembagi 5 state. Kayu Mahoni juga memiliki kecocokan 100\%, Damar $50 \%$, dan kayu Sengon tidak memiliki kecocokan.

\section{KESIMPULAN DAN SARAN}

Kesimpulan dari hasil analisis dan pembahasan yang telah dilakukan dapat disimpulkan sebagai berikut:

\section{A. Dari hasil simulasi pembagian 3 state}

Hasil prediksi untuk periode selanjutnya prosentase tertinggi pada interval 1 sebagai berikut:

Kayu Pinus : 95\%

Kayu Mahoni : $96 \%$

Kayu Sengon : 99\%

Kayu Damar : $98 \%$

Prediksi pada pembagi 3 state untuk 4 periode kedepan masing-masing kayu memiliki kecocokan $100 \%$ terhadap data yang ada, akan tetapi untuk kayu Damar memiliki kecocokan $75 \%$.

\section{B. Hasil simulasi pembagian 4 state}

Pada prediksi hasil simulasi pembagi 4 state, kayu Pinus dan Kayu Mahoni memiliki kecocokan dengan data $100 \%$, untuk kayu Damar 50\%.

\section{Hasil simulasi pembagian 5 state}

Dan untuk prediksi hasil simulasi pembagi 5 state, kayu Pinus dan Mahoni memiliki kesesuaian 100\% dengan data aktualnya, dan kayu Damar memiliki kesesuain 50\%. Kayu Sengon tidak memiliki kesesuaian karena syarat matriks probabilitas transisinya tidak terpenuhi.

Dengan adanya prediksi hasil produksi kayu bundar tersebut diharapkan mampu memberikan informasi yang dapat membantu pihak yang bersangkutan dalam membuat keputusan. Terutama untuk pihak Perhutani maupun pengolah kayu agar dapat mempermudah dalam mengambil kebijakan.

\section{DAFTAR PUSTAKA}

[1] Ilmugeografi.com, "Website Pusat Studi Ilmu Geografi Indonesia." [Online]. Available: www.ilmugeografi.com.

[2] Perhutani, "Website BUMN Perhutani." [Online]. Available: www.bumn.go.id/perhutani.com .

[3] Q. Zhou, "Application of Weighted Markov Chain in Stock Price Farecasting of China Sport Industri," Int. J. u- e-Serv. Sci. Technol., vol. 8, no. 2, pp. 219-226, 2015.

[4] Mustakim and E. Saputra, "Aplikasi Prediksi Hasil Tanaman Palawija di Kabupaten Indragiri Hilir Menggunakan Metode Markov Chains," J. Sains, Teknol. dan Ind., vol. 9, no. 2, pp. 50-59, 2012.

[5] S. Nawangsari and et al, "Konsep Markov Chains Untuk Menyelesaikan Prediksi Bencana Alam di Wilayah Indonesia dengan Studi Kasus Kotamadya Jakarta Utara," J. Ilm. Inform., vol. 5, 2008.

[6] S. Syafruddin and et al, "Aplikasi Analisis Rantai Markov untuk Memprediksikan Status Pasien Rumah Sakit Umum Daerah Kabupaten Barru," J. Nat. Sci., vol. 3, no. 3, pp. 313-321, 2014.

[7] S. Halim, "Penelitian Operasional Rantai Markov," J. Tek. Ind., vol. 2, p. 57, 2013.

[8] K. Ninggar, "Peramalan Pergerakan Harga Saham Perusahaan Go Public Menggunakan Rantai Markov," Surabaya, 2016. 